\title{
ПРОБЛЕМЫ ОБЕСПЕЧЕНИЯ ФИНАНСОВОЙ УСТОЙЧИВОСТИ БАНКОВСКОЙ СИСТЕМЫ РОССИЙСКОЙ ФЕДЕРАЦИИ
}

\author{
(c) 2018 Аверченко Олег Дмитриевич \\ кандидат экономических наук, преподаватель кафедры «Финансовые рынки» \\ Российский экономический университет им. Г.В. Плеханова \\ 117997, г. Москва, Стремянный пер., д. 36 \\ E-mail: Averchenko.OD@rea.ru
}

Предмет. Банковская система Российской Федерации находится в стадии трансформации под воздействием внешних факторов, стагнации в национальной экономике и изменения стандартов регулирования и надзора. Масштабные процессы трансформации банковской системы требуют усилий по сохранению ее финансовой устойчивости.

Цель. Целью данной статьи является исследование проблем обеспечения и направлений повышения финансовой устойчивости банковской системы Российской Федерации.

Методология. В настоящей работе с помощью методов анализа, логического обобщения, научной абстракции, а также системно-структурного анализа исследованы проблемы обеспечения финансовой устойчивости банковской системы Российской Федерации.

Результаты. Проведена оценка и выявлены проблемы обеспечения финансовой устойчивости отечественной банковской системы. Выделены основные направления повышения финансовой устойчивости российской банковской системы.

Выводы. Сделан вывод о том, что важную роль в повышении финансовой устойчивости банковской системы играет совершенствование процедур мониторинга. Чтобы повысить финансовую устойчивость банковской системы целесообразно усилить механизмы пруденциального надзора.

Ключевые слова: финансовая устойчивость, банковская система, ликвидность, стресс-тестирование, пруденциальный надзор.

Несмотря на многочисленные научные исследования, общепринятый подход определения термина «финансовая устойчивость» в академической литературе отсутствует. Чаще всего финансовую устойчивость рассматривают с позиции способности банковской системы эффективно противостоять негативным факторам внешней и внутренней среды и выполнять свои основные функции - платежеспособность, эффективное распределение, использование и перераспределение финансовых потоков [9].

Обеспечению финансовой устойчивости банковской системы существенно содействует, прежде всего, своевременность и качество ее оценки. В современных условиях снижения степени стабильности и надежности банков, регулярного изменения условий внешней среды, где коммерческие банки осуществляют свою деятельность, требуется глубокая оценка финансовой устойчивости банковской системы и поиск способов ее повышения.

Оценивать финансовую устойчивость банковского сектора можно следующими подходами:
1) анализ однородных групп и коэффициентный анализ;

2) системы оценки рейтингами;

3) комплексная система оценки рисков в банковской сфере;

4) системы «предыдущего реагирования» (статистические модели);

5) микро- и макропруденциальный анализ.

В табл. 1 приведена характеристика подходов к оценке финансовой устойчивости банковской системы, примеры использования, методы анализа, недостатки и преимущества каждого из них. Следует отметить, что приведенные в табл. 1 подходы к оценке имеют ряд региональных отличий. Это напрямую связано со структурными и историческими характерными чертами развития банковских систем разных стран.

Одной из важнейших составляющих оценки финансовой устойчивости банковской системы Российской Федерации является макропруденциальное стресс-тестирование. В докладе МВФ макропруденциальный стресс-тест имеет следующее определение - «стресс-тест, который учитывает реакцию институтов финансового 


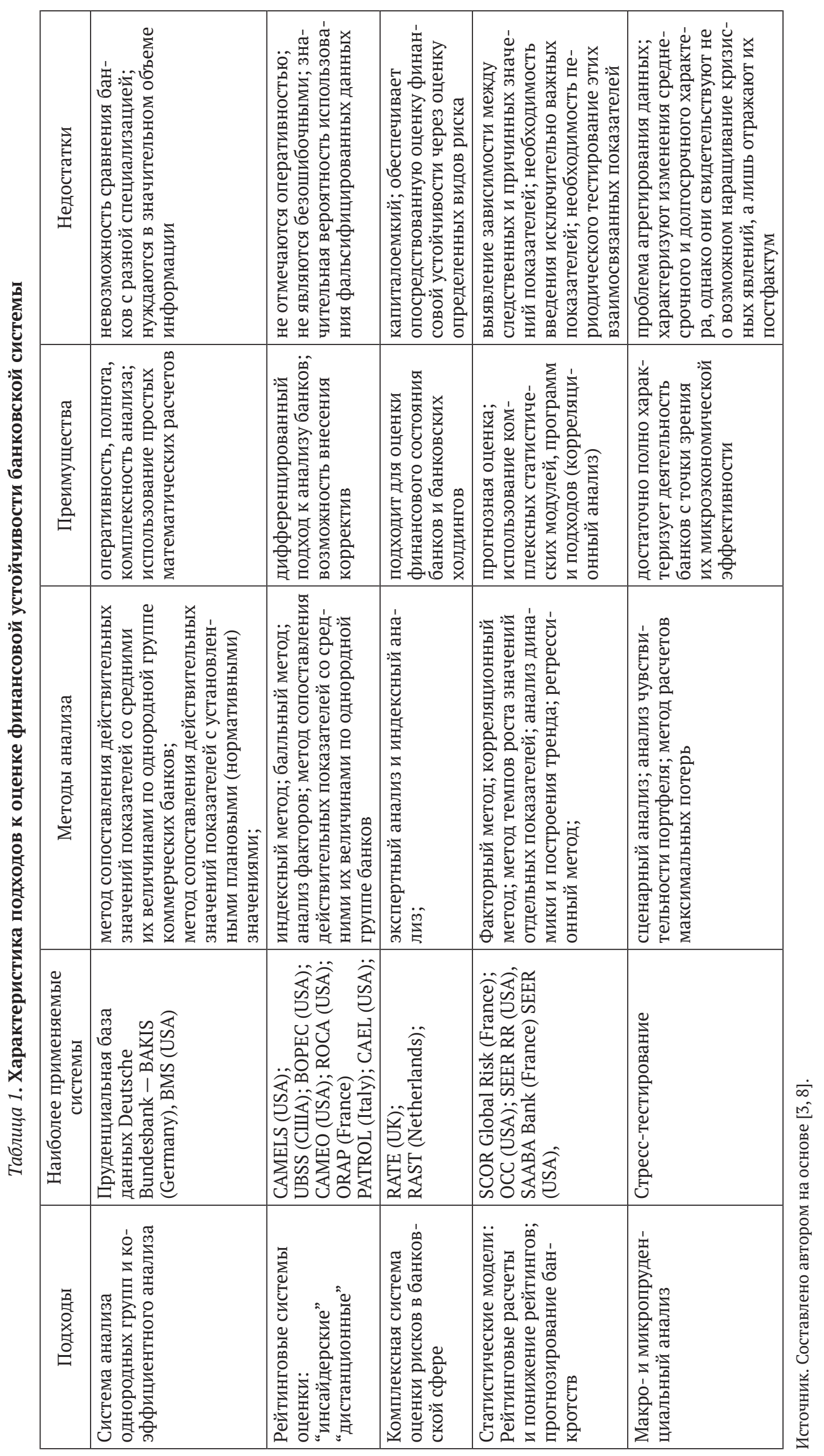


сектора на экономические потрясения и их взаимодействие, направленное на обследование устойчивости всей финансовой системы, а не избранных финансовых институтов» [10].

Центральный банк России начал осуществлять стресс-тестирование национальной банковского системы с 2003 года. Результаты данных надзорных стресс-тестов, начиная с 2004 г., опубликуются в отчете о развитии российского банковского сектора [5].

Исследование финансовой устойчивости банковской системы Российской Федерации проводится также путем анализа основных показателей ее деятельности, ее оценки на основе коэффициентного анализа и финансовых индикаторов.

Важным при определении финансовой устойчивости банковской системы является качество экономической конъюнктуры. Целесообразно выявить уровень интегрированности банковский системы с экономикой страны, что позволит более верно осуществить оценку влияния на устойчивость банковского сектора от экономической конъюнктуры.

Индикаторы, определяющие динамику и состояние развития банковской сектора в отечественной экономике (рисунок 1), показывают прогрессивную закономерность, что подтверждает увеличение присутствия и интеграции национального банковского сектора в отечественную экономику. Совокупные активы банковского сектора России на 01.01. 2018 г. составляли 85191,8 млрд. руб., что соответствует 92,6\% от ВВП страны. За последние годы происходит увеличение кредитования экономики. Незначительно, но все же растет собственный капитал банковского сектора. Можно наблюдать четкую корреляция между показателями национального банковского сектора и ростом национальной экономики.

Кризисная ситуация в отечественной банковской системе, из-за различных внешних и внутренних факторов, способствовала увеличению отрицательных финансовых показателей в банковском секторе. Общий объем прибыли (по данным Банка России) сократился с 993,6 млрд. руб. на 01.01. 2014 г. до 589,1 на 01.01. 2015 г. и далее до 192 млрд. руб. к началу 2016 г., а убытки выросли до 543,9 млрд. руб. Начиная с 2016 года стабилизировался валютный рынок, финансовое состояние заемщиков улучшилось, произошло внедрение новых внутрибанковских нормативов, переход на новые стандарты международной отчетности МСФО 9 (резервы по потерям по кредитам должны создаваться на протяжении всего срока кредита), улучшился риск-менеджмента в банках. Все это способствовало снижению объемов создаваемых резервов на потенциальные потери по кредитам. Грамотная процентная политика банков сказалась на росте процентного дохода. Активно начали происходить интеграционные процессы в финансовой сфере, что привело к расширению спектра услуг для клиентов и, следовательно, росту ко-
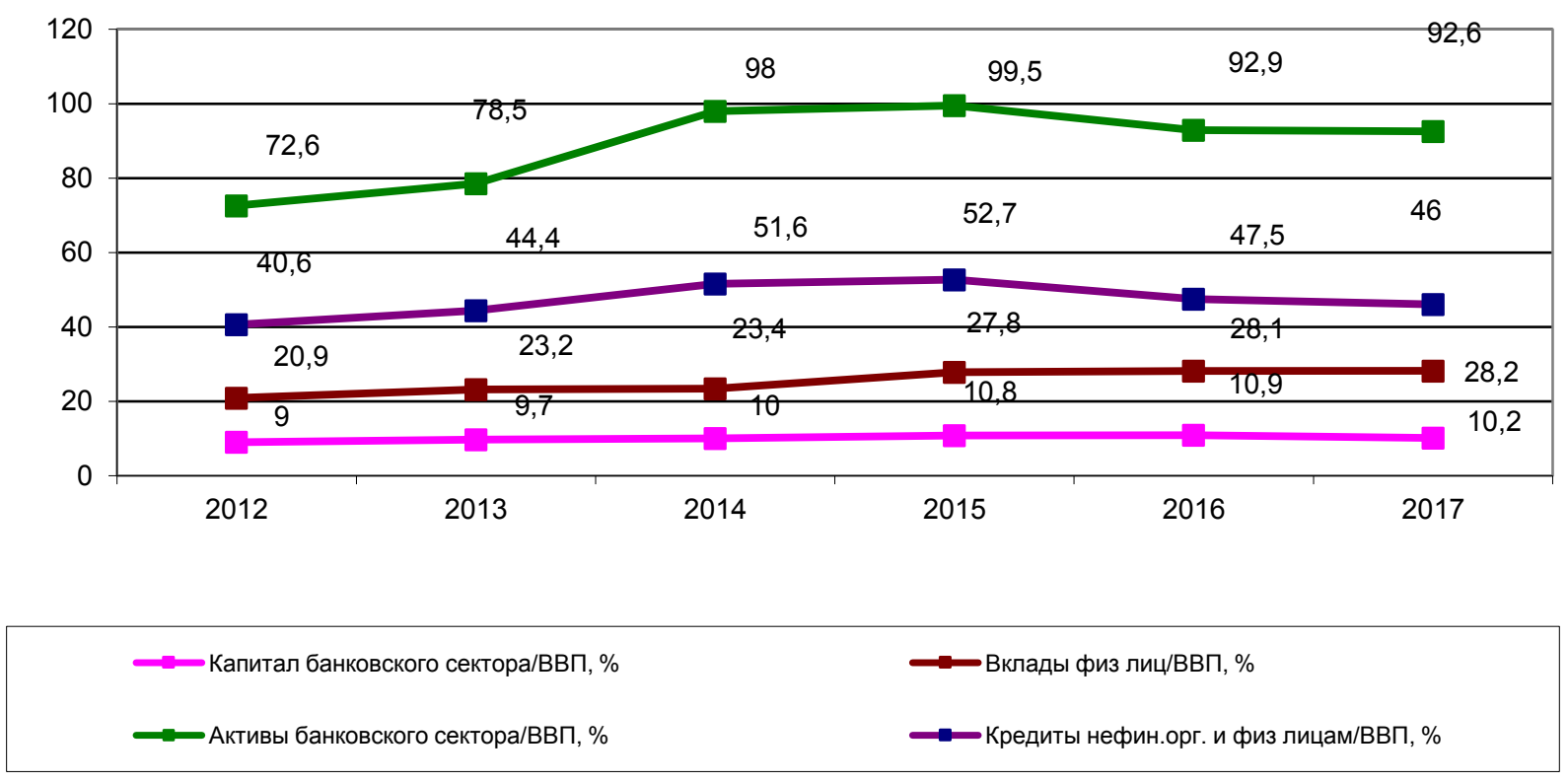

Puc. 1. Динамика показателей банковского сектора в экономике страны Источник. Составлено автором на основе [4] 
миссионных доходов. Следовательно, прибыль банковских организаций за девять месяцев 2018 г. значительно выросла и составили 900,5 млрд. руб., что уже соответствует показателям 2013 года, т.е. до кризисного периода (рисунок 2).

Одними из основных причин снижения показателей прибыльности банковского сектора в 2014-2016 гг. явилось влияние внешних факторов, нестабильность на финансовых рынках, рост количества клиентов с просроченной задолженностью, закрытие рынков капиталов для отечественных кредитных институтов и т.д. При этом следует отметить, что уровень совокупных активов банковского сектора был практически стабилен и даже показывал рост (рисунок 3).

Согласно рисунку 3 активы банковского сектора до 2015 года увеличивались существенно, а по итогам 2015 г. динамика роста совокупных активов изменилась. Рост составил всего лишь $6,9 \%$. Такой показатель значительно отличается от предыдущих периодов. Несомненно, замедление роста активов связанно с замедлением экономического роста в стране. Начиная с 2014 г. темпы роста ВВП России начали существенно снижаться, с 30,2\% в 2011 году до 3,3\% по итогам 2016 года. Данное снижение отразилось на всех сферах жизни страны, в том числе повлияло и на банковский сектор экономики. Банковская система страны замедлила свое развитие. По

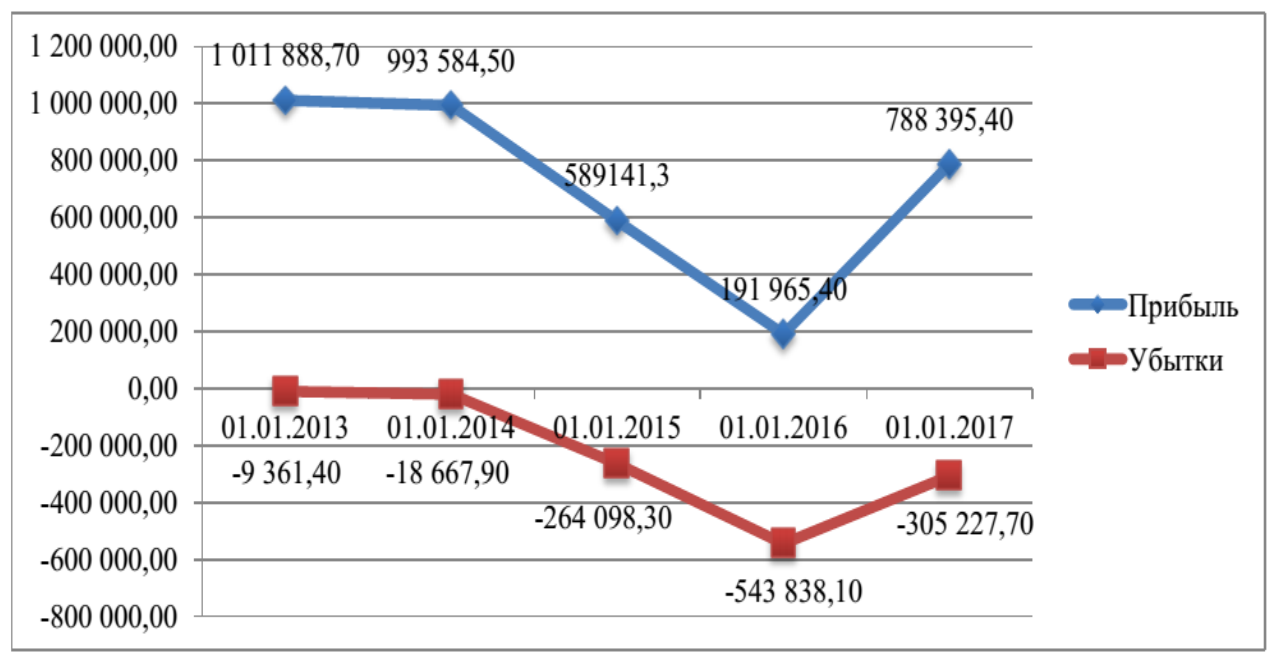

Puc. 2. Динамика показателей финансового результата банковского сектора за период 2012-2017 гг., млн. руб. Источник.[4].

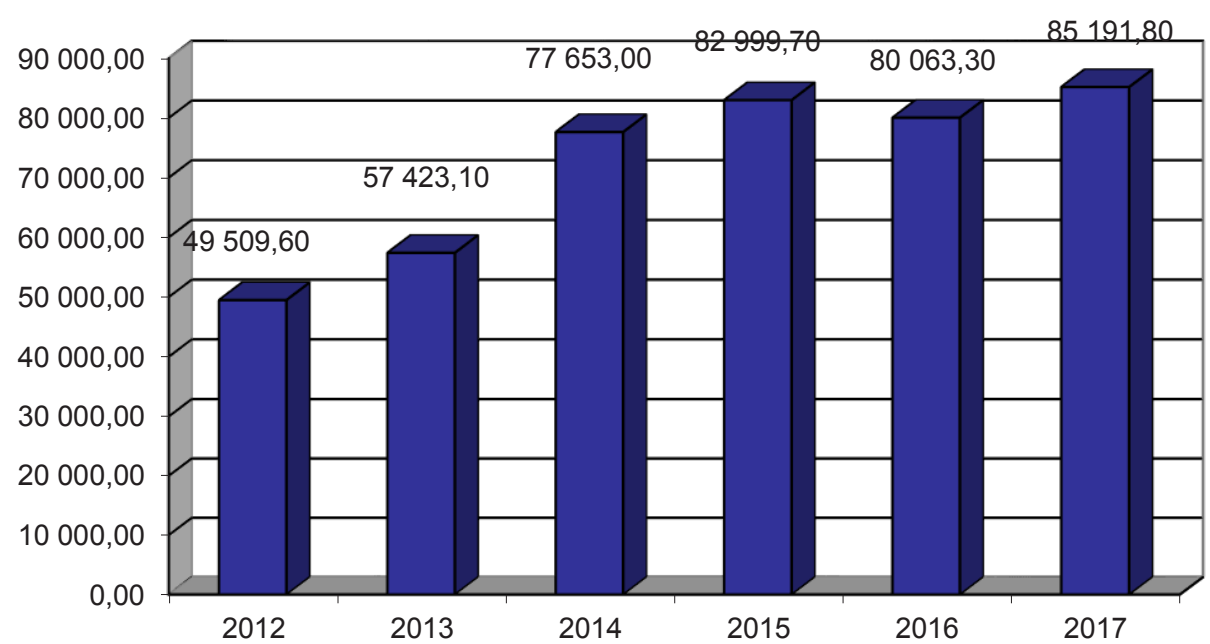

Puc. 3. Динамика активов банковского сектора Российской Федерации, млрд. руб. Источник. Составлено автором на основе [4]. 
итогам 2016 года активы банковского сектора и вовсе сократились на 2,9 трлн. руб., это стало первым падением активов банков с 1998 г. Совокупная величина активов банковского сектора в 2017 г. выросла на 6,4\%. Тем не менее, в связи с более быстрым ростом номинального ВВП, отношение активов банковского сектора к ВВП снизилось с 92,9 до 92,6\%.

Основным критерием финансовой устойчивости и качественного состояния банковской системы является ликвидность. В течение 20122014 гг. отечественный банковский сектор находился в состоянии увеличения дифицита ликвидности, однако уже в начале 2015 г. тенденция изменилась, что в итоге привело к формирова- нию профицита уже в середине 2016 г. (рисунок 4). Начиная, с данного периода профицит ликвидности перешел в стадию роста. По состоянию на 03.09.2018 г. профицит ликвидности в национальной банковской системе составлял 3423,9 млрд. руб.

Важным индикатором запаса прочности банковской системы служит достаточность капитала. Без учета банков, которые проходят процедуру финансового оздоровления, уровень достаточности капитала на конец 2017 г. составил $14,7 \%$ (рисунок 5).

Регулярно проводимые стресс-тесты показывают, что совокупный показатель достаточности капитала по банковскому сектору остается

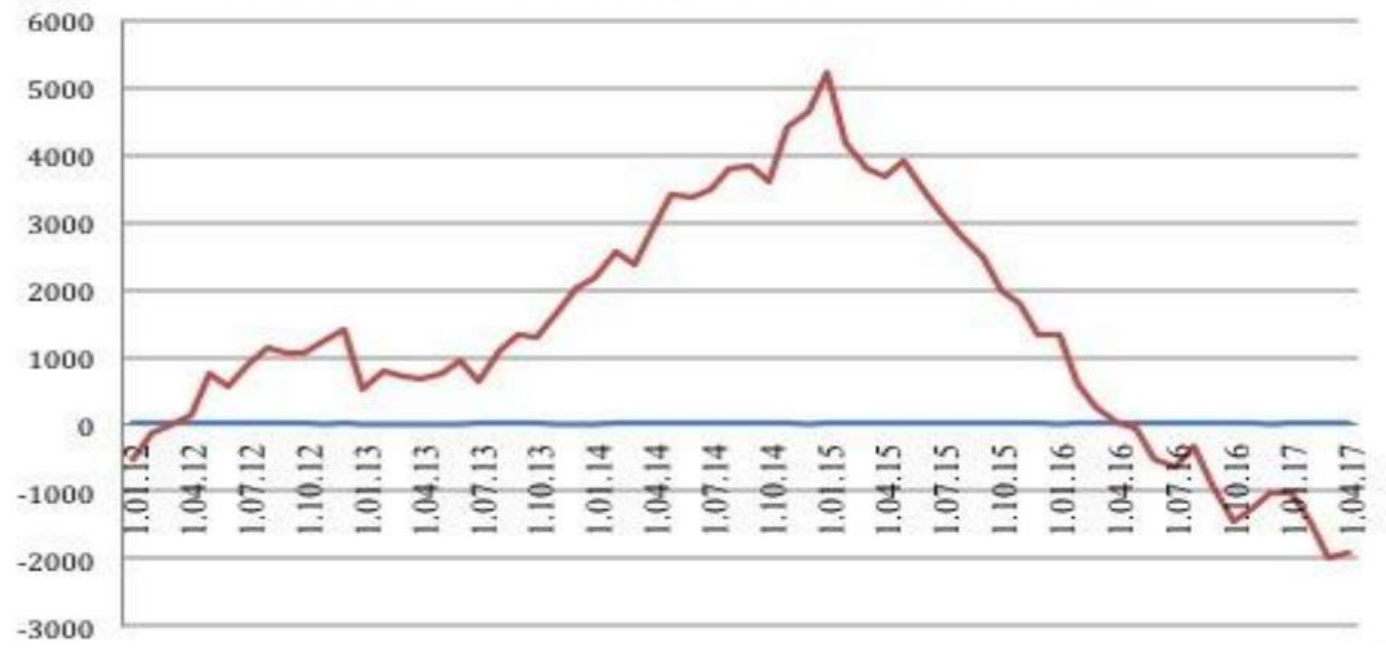

Puc. 4. Уровень ликвидности банковской системы РФ, млрд. руб. Источник. [6].

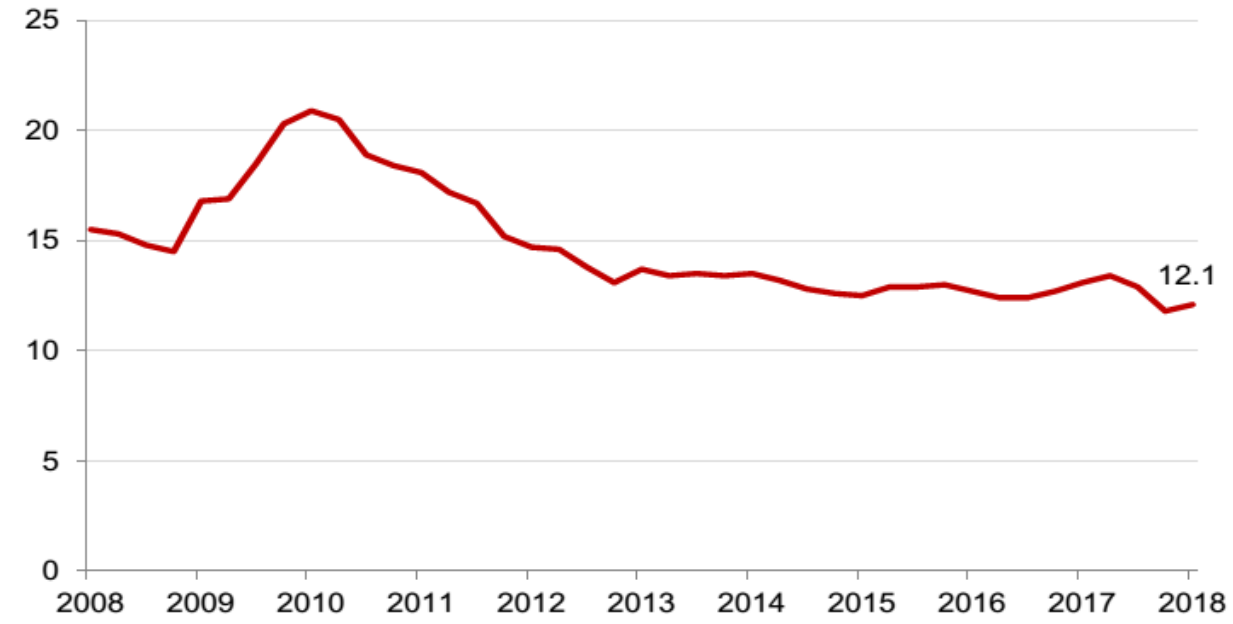

Puc. 5. Норматив достаточности капитала,\% Источник. [1]. 
около регулятивного минимума. Таким образом, устойчивость банковского сектора Российской Федерации находится на удовлетворительном уровне, а с точки зрения динамики (после некоторого ухудшения в период кризисных явлений) постепенно повышается.

Несмотря на некоторые успехи, в настоящее время финансовая устойчивость российской банковской системы имеет ряд проблем. Главными из них являются:

- кредитование аффилированных структур, т.е. кредитование своих же собственников, в ущерб самому банку и его кредиторам, и вкладчикам;

- завышение стоимости активов, т.е. осуществление притворных сделок для создания видимости качества и востребованности неликвидных активов;

- фиктивная капитализация банков, путем увеличения собственного капитала за счет средств самой кредитной организации;

- дефицит «длинных» ресурсов, из-за ограниченного доступа к рынку капиталов;

- нехватка собственного капитала и слабое управления собственными издержками в кредитных организациях;

- устремленность кредитных организаций извлечь наибольшую прибыль при этом, не учитывая последствия для финансовой устойчивости самого банка;

- низкий уровень управления рисками в банковской сфере.
Например, бурный рост выпуска кредитных карт банками, несопоставимый с доходами населения, провоцирует образование нового финансового пузыря на рынке кредитования, способного привести к разбалансировке банковского сектора страны [2].

В рамках политики по повышению финансовой устойчивости банковской системы на протяжении последних четырех лет идет интенсивная борьба с недобросовестными участниками рынка, которые представляют угрозу для финансовой устойчивости. За это время (по состоянию на 1 августа 2018 г.) было отозвано 358 банковских лицензий [7].

Ввиду роста численности крупных частных банков, которые попали под санацию или отзыв лицензии, в банковской системе стабильно возрастает доля госбанков: среди крупнейших банков практически не осталось независимых частных кредитных организаций, доля госбанков в кредитовании юридических лиц превысила $80 \%$, а в кредитовании физлиц - 70\% (рисунок 6).

По мнению экспертов, огосударствление банковского сектора влечет за собой ряд существенных рисков, которые в конечном счете сводятся к тому, что банковский сектор может перестать удовлетворять потребности отдельных сегментов в реальном секторе экономики, что в худшем сценарии может спровоцировать развитие рынка квазибанковских услуг. Это уже можно наблюдать на примере того, что микро-

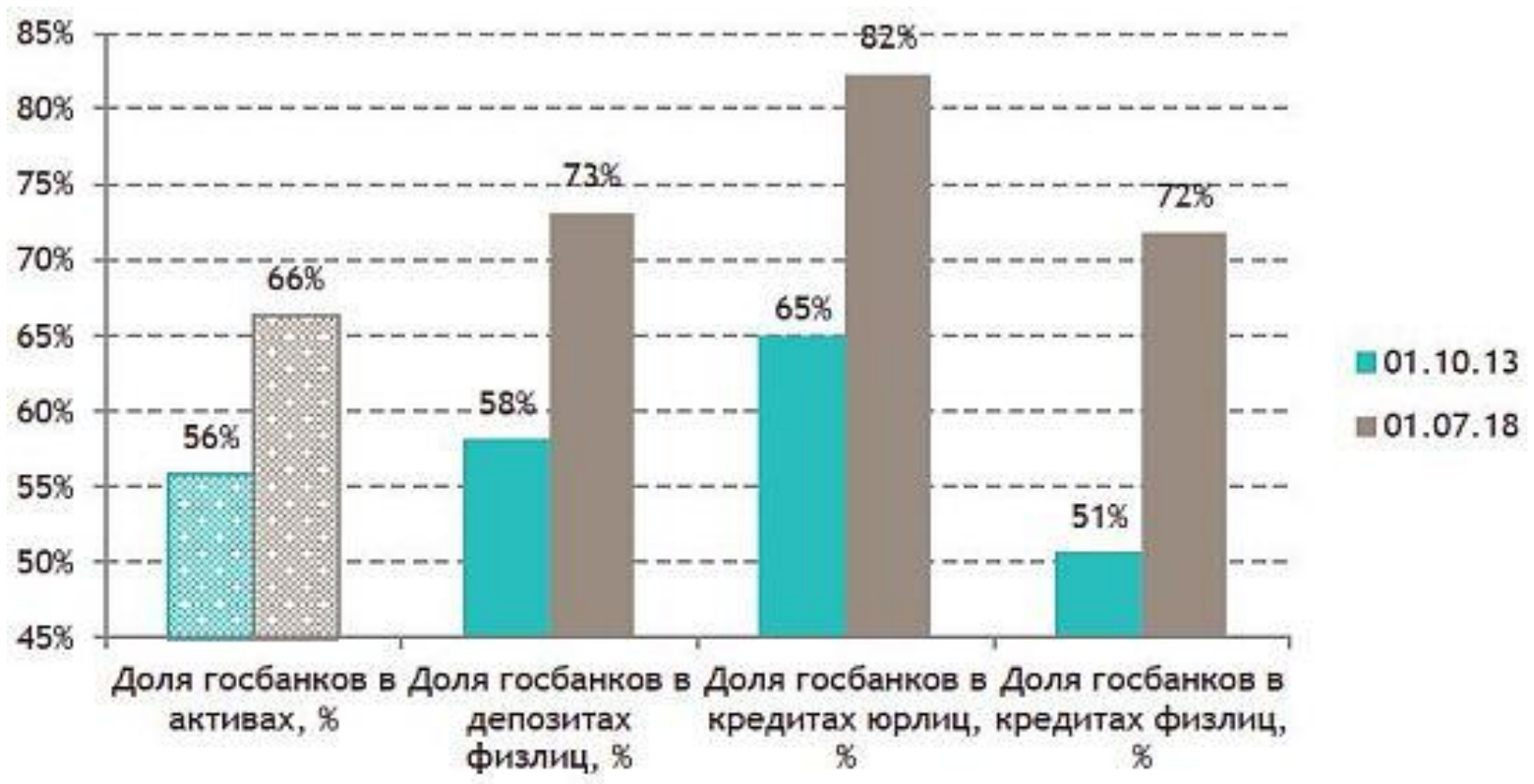

Puc. 6. Динамика доли госбанков в разрезе различных балансовых показателей Источник. [7]. 
финансовые организации (МФО) массово увеличивают сроки и суммы займов, тем самым приближая их к традиционным банковским кредитам. Даже учитывая то, что занимать у МФО значительно дороже, чем у традиционных банков, востребованность на такие услуги и продукты есть.

По мнению автора, чтобы повысить финансовую устойчивость банковской системы целесообразно усилить механизмы пруденциального надзора.
Важную роль в повышении финансовой устойчивости банковской системы играет совершенствование процедур мониторинга. С одной стороны, это не должно создавать дополнительного регуляторного давления на банки, что позволит системе качественно развиваться. С другой стороны, осознание прозрачности системы перед регулятором за счет эффективного мониторинга будет удерживать банки от незаконных действий.

\section{Библиографический список}

1. Итоги десятилетия 2008-2017 годов в российском банковском секторе: тенденции и факторы. [Электронный ресурс]. - [Режим доступа]: https://www.cbr.ru/Content/Document/File/43933/wps31.pdf

2. Ковалева Э.Р., Кабашева И.А. Оценка потенциала роста доходов банков от операций с банковскими картами // Конкурентоспособность в глобальном мире: экономика, наука, технологии. 2017. № 2-1 (29). С. 118-122.

3. Некоторые подходы к разработке системы индикаторов мониторинга финансовой стабильности / С. М. Дробышевский и др. Москва. 2006. 305 с.

4. Обзор банковского сектора Российской Федерации. [Электронный ресурс]. - [Режим доступа]: http://www. cbr.ru/analytics/? PrtId=bnksyst

5. Отчет о развитии банковского сектора и банковского надзора. [Электронный ресурс].- [Режим доступа]: http://www.cbr.ru/publ/nadzor

6. Структурный дефицит/профицит ликвидности банковского сектора. [Электронный ресурс].- [Режим доступа]: http://www.cbr.ru/hd_base/bliquidity

7. астные банки: есть ли шансы на выживание? // Аналитический центр при Правительстве Российской Федерации. Сентябрь 2018. 20 с.

8. Carson C.S. Financial Soundness Indicators // International Monetary Fund. - 2003. - May, 14. - P. 43.

9. Financial stability review // European Central Bank. November 2006. 18 p.

10. IMF Working Paper. Designing Effective Macroprudential Stress Tests: Progress So Far and the Way Forward. D. Demekas, June 2015. [Electronic Resource]. - Mode of access: https://www.imf.org/external/pubs/ft/wp/2015/ wp15146.pdf 